\title{
Trilha do CerRado: Jogo PaRA EnSINO do bioma Cerrado
}

\author{
TRAIL OF THE CERRADO: GAME FOR TEACHING THE CERRADO BIOME
}

DOI: 10.23926/RPD.2526-2149.2020.v5.n2.p1076-1092.id725

\author{
Alexandre Ferreira \\ Nunes \\ Mestre em Ensino de \\ Biologia (UnB) \\ Professor na Instituição \\ Colégio Estadual Herta \\ Layser O’Dwyer \\ alexandre.nunes@seduc.go.g \\ $\underline{\text { ov.br }}$
}

\section{João Paulo Cunha de Menezes \\ Doutor em Ciências (UFLA) \\ Professor Adjunto na \\ Universidade de Brasília \\ (UnB) \\ Doutor na Instituição UFLA. \\ jpaulo_bio@hotmail.com}

Resumo: Os jogos têm sido considerados cada vez mais popular no processo de ensino-aprendizagem. No entanto, sabemos pouco sobre a eficácia dos jogos na aquisição de conhecimentos dos estudantes. Considerando a importância desta ferramenta no ensino, este trabalho teve por objetivo avaliar o potencial de um jogo de tabuleiro em trabalhar o bioma Cerrado com estudantes do ensino médio. A aplicação do jogo seguiu os Três Momentos Pedagógicos e foi avaliada com base na em observações de campo, na Taxonomia de Bloom revisada e com auxílio de um questionário. Desta forma, foi possível observar que a atividade conseguiu atingir os estudantes, desenvolvendo e aprimorando os conceitos do bioma Cerrado. Esses conceitos foram verificados conforme avaliação proposta segundo a Taxonomia de Bloom. Desta forma, acreditamos que o uso de jogos para tratar temas tais como os biomas têm grande potencial de ser utilizado no ensino médio.

Palavras-chave: Ensino de Biologia; Jogos Didáticos; Cerrado.

Abstract: Games have been considered increasingly popular in the teaching-learning process. However, we know little about the effectiveness of games in acquiring students' knowledge. Considering the importance of this tool in teaching, this work aimed to evaluate the potential of a board game in working the Cerrado biome with high school students. The application of the game followed the Three Pedagogical Moments and was evaluated based on field observations, the revised Bloom Taxonomy and with the help of a questionnaire. In this way, it was possible to observe that the activity was able to reach the students, developing and improving the concepts of the Cerrado biome. These concepts were verified according to the proposed evaluation according to the Bloom Taxonomy. In this way, we believe that the use of games to address topics such as biomes has great potential to be used in high school.

Keywords: Teaching Biology; Didactic Games; Cerrado. 


\section{INTRODUÇÃO}

Apesar de décadas de pesquisa, ainda sentimos uma falta de conteúdo apropriado e interessante que envolva os estudantes e tenha o potencial de melhorar o processo de ensinoaprendizagem. Desta forma, apresentando aqui as conclusões da pesquisa sobre o uso de um jogo focado no ensino do bioma cerrado como um recurso capaz de envolver ativamente os estudantes do ensino médio em conteúdos ministrado na disciplina de biologia, neste caso específico o bioma Cerrado. Quando nos referimos a jogos, queremos dizer 'atividades imersivas, voluntárias e agradáveis, nas quais um objetivo desafiador é perseguido de acordo com as regras acordadas. Este piloto foi realizado em uma escola pública no estado de Goiás para avaliar as percepções de estudantes e a aceitação no processo da aprendizagem baseada em jogos.

Tendo em mente o aspecto cooperativo, prazeroso e facilitador da aprendizagem baseada em jogos, este trabalho teve como objetivos: i) investigar a contribuição de um jogo de tabuleiro para a compreensão de conceitos e processos relacionados a ao bioma Cerrado por estudantes do ensino médio; ii) acessar a jogabilidade e aceitação do jogo entre estudantes de uma escola pública; e iii) avaliar a percepção do estudante quanto a aprendizagem e sua capacidade de aplicar os conceitos biológicos apreendidos ao jogar o jogo. A escolha de um jogo de tabuleiro (e não um jogo eletrônico) foi baseada na relação custo-benefício, pois os jogos eletrônicos exigiriam uma estrutura ausente em muitas escolas, especialmente as públicas.

\section{REFERENCIAL TEÓRICO}

O estudo dos biomas é parte integrante dos currículos do ensino fundamental quanto no ensino médio podendo chegar até o nível superior como é o caso dos cursos de Ciências Biológicas e Ciências Naturais. No entanto, os livros didáticos adotados pelos professores abordam o tópico de maneira semelhante, pouco aprofundado. Os biomas são frequentemente oferecidos como uma unidade em livros didáticos, ilustrados com algumas figuras e definidos por características-chave, como clima, estrutura da vegetação e ecofisiologia (ou seja, adaptações dos organismos ao meio ambiente e fisiologia subjacente (CRISP, 2006; RICHARDSON, 2009; SILVA et al., 2015; CARVALHO; SILVA, 2019).

Os biomas são as principais unidades de organização do mundo natural, mas os livros didáticos frequentemente isolam o tópico e não o conectam a unidades naturais menores, como ecossistemas, comunidades e populações (RICHARDSON, 2009). Desta forma, os estudantes costumam ter problemas para visualizar estes biomas, suas localizações geográficas, 
relacionando com outras unidades organizacionais e biomas com suas próprias vidas. Segundo Richardson (2009), os professores costumam usar vídeos educacionais para fornecer visualizações de biomas e complementar o livro. No entanto, os vídeos não envolvem ativamente os estudantes, desta forma, uma abordagem mais prática e envolvente que poderia ser utilizada para o ensino de biomas envolve o uso de jogos didáticos.

O jogo didático pode ser conceituado como um instrumento de aprendizagem, que visa o desenvolvimento intelectual e social de um grupo de indivíduos. A ideia de inserir jogos no contexto de sala de aula para facilitar o processo de ensino-aprendizagem não é um conceito novo, já que educadores e pesquisadores discutem tal ferramenta desde a década de 1960 (SCARFE, 1962). No entanto, o uso de jogos didáticos em sala de aula tem aumentado constantemente à medida que nova pesquisas apontam para o alto potencial que tal ferramenta apresenta na facilitação no processo de ensino-aprendizado (GARRIS; AHLERS; DRISKELL, 2002) como no desenvolvimento social dos estudantes. Além disso, como as aulas de ciências tradicionais geralmente são descontextualizadas e se concentram principalmente na memorização rotineira de fatos, jogos como recurso didático tem o potencial de apoiar a participação ativa dos estudantes e são considerados uma forma de abordagem para desenvolver o interesse dos mesmos em investigações científicas e fornecer aos estudantes conhecimentos e habilidades de que precisam (CHENG et al., 2017).

Como os jogos criam um contexto praticamente imersivo (DEDE, 2009), no qual os estudantes podem experimentar e repetir experimentações que dificilmente serão realizadas em suas vidas diárias, acredita-se que seu uso em ambientes educacionais possa apresentar diversos ganhos cognitivos (CHENG; ANNETTA, 2012), tais como: facilita a aquisição de conhecimento (SHABANEH; FARRAH, 2019), melhora a memória e promovem habilidades específicas como resolução de problemas e colaboração (JUSTICE; RITZHAUPT, 2015), visualizando adequadamente ideias abstratas de determinados tópicos no ambiente do jogo. Ao mesmo tempo, o uso de jogos em sala de aula melhorar a motivação dos estudantes (PAPASTERGIOU, 2009), como também existem elementos nos jogos que podem contribuir para diferentes estilos de aprendizagem (BYL; BRAND, 2011).

A construção do conhecimento que ocorre quando se utiliza dos jogos é fundamentalmente diferente das experiências de aprendizagem associadas às ferramentas tradicionais de ensino (VOGRINC; ZULJAN, 2010). O uso de jogos didáticos implica no estabelecimento de metas de aprendizagem nas quais os estudantes mantem o prazer garantindo que absorvam e adotem o conhecimento gerado (SKILBECK, 2017). Kolb (1984) descreve a 
aprendizagem como um processo pelo qual o conhecimento é criado pela transformação de experiências (KOLB, 1984). Esse processo tem quatro fases: (1) experiência concreta, (2) observação reflexiva, (3) conceitualização abstrata e (4) experimentação ativa. Os jogos têm o potencial de facilitar e aprimorar esse processo, fornecendo uma experiência ativa na qual o estudante conceitua o conhecimento e depois experimenta ativamente o conceito do jogo.

\section{Metodologia}

Optou-se por um estilo de jogo bastante conhecida entre os estudantes, o jogo de tabuleiro do tipo "trilha", que toma pouco tempo para ser explicado e aplicado, denominado "Trilha do Cerrado". Além disso, há interação e socialização entre os estudantes nos momentos das perguntas e das ações propostas. A escolha do tema teve como premissa a ausência de conteúdos mais aprofundados nos livros didáticos possibilitando trabalhar diferentes conteúdos em ecologia.

O jogo "Trilha do Cerrado" tem como intuito ensinar questões sobre o bioma, após reunir características das fitofisionomias do Cerrado de forma mais prazerosa para que o estudante possa obter a motivação necessária para com os assuntos abordados. O jogo é composto por um tabuleiro, um dado e cartas contendo as perguntas, informações e outros aspectos do bioma Cerrado (para maiores informações sobre o jogo verificar o trabalho de Nunes (2020)) (Figura 1).

Figura 1 - Modelo do tabuleiro do jogo didático para o estudo do bioma Cerrado

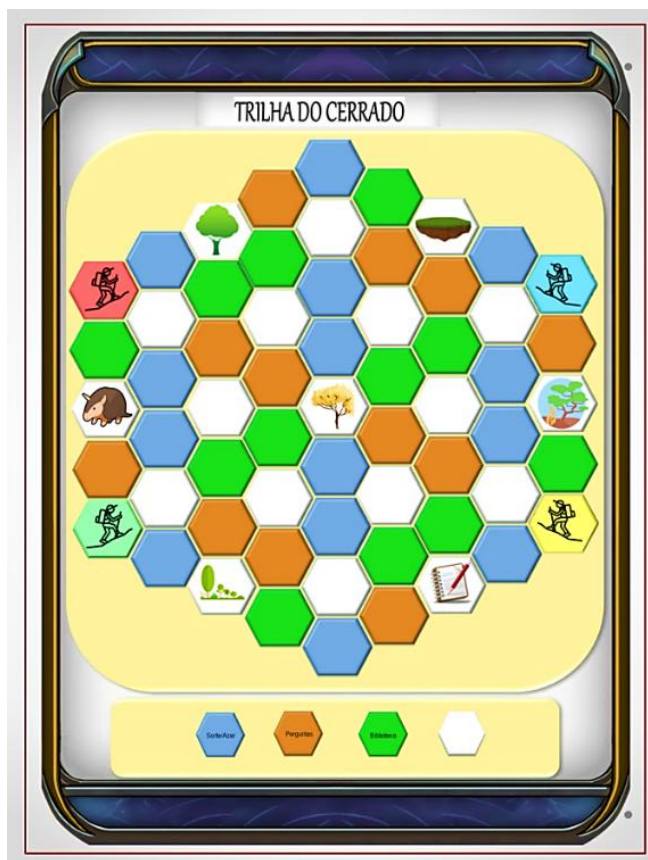

Fonte: Alexandre Ferreira Nunes (2019) 
Para a implementação da prática, utilizou-se do Módulo Didático de Delizoicov e Angotti (1991), que apresenta Três Momentos Pedagógicos. São eles: i) Problematização inicial; ii) organização do conhecimento e iii) aplicação do conhecimento.

Foram escolhidos os estudantes da $3^{\text {a }}$ série do Ensino Médio como sujeito de pesquisa, pelo fato do tema bioma ser abordados nesta série. O conteúdo bioma é abordado dentro do conteúdo "Divisões e Diversidade da Biosfera" que faz parte do Eixo Temático Evolução e Ecologia dos Seres Vivos, conforme o Currículo de Referência da Rede Estadual de Educação de Goiás na disciplina de Biologia. Antes da partida, os estudantes foram agrupados em equipes com quatro participantes, sendo que cada tabuleiro poderia abrigar até quatro equipes (16 participantes), os estudantes ficaram livres para trocar informações entre si, até alcançar o seu objetivo.

Quanto à natureza, o presente trabalho trata-se de uma pesquisa aplicada. O intuito foi obter informações pudessem promover uma aplicação prática, para soluções de problemas (BARROS; LEHFELD, 2000). Os dados foram coletados por gravação de imagem e som, registro em caderno de campo e uso de questionário. Todo material foi interpretado e analisado utilizando da metodologia de Análise de Conteúdo proposta por Bardin (2004). Fundamentando-se em Bardin (2004) a análise de conteúdo seguiu as etapas: (i) pré-análises ou leituras flutuantes (ii) exploração do material; categorização; (iii) tratamento, interferências e interpretação dos resultados. Na primeira das etapas, a pré-análise, realizou-se a leitura flutuante, que implicou em conhecer inicialmente os instrumentos respondidos e criar familiaridade com ele, e uma organização do material que foi investigado. Também foi adotada a Taxonomia de Bloom revisada, (FERRAZ, BELHOT, 2010) para avaliar a o potencial do jogo. A aprovação ética para a coleta e análise dos dados foi obtida com o Certificado de Apresentação de Apreciação Ética número 18323619.4.0000.0030 no comitê de Ética em Pesquisa da Universidade de Brasília. Códigos foram usados para proteger a identidade dos estudantes.

\section{Resultados}

Os resultados serão apresentados divididos em três partes. A primeira é a aplicação do jogo conforme os Três Momentos Pedagógicos (3MP). A segunda parte é a observação da prática a partir da análise da Taxonomia de Bloom, e por último a avaliação da proposta, por meio das respostas do questionário realizado pelos participantes do jogo "Trilha do Cerrado". 
O jogo "Trilha do Cerrado", foi aplicado seguindo os Três Momentos Pedagógicos (DELIZOICOV; ANGOTTI, 1991), sendo: "Problematização Inicial”, "Organização do Conhecimento" e "Aplicação do Conhecimento". No momento pedagógico "Problematização Inicial", os estudantes foram encaminhados até o laboratório de ciências da escola, onde participaram da aplicação. Nesse momento, todos foram convidados a formarem equipes com quatro participantes, ficando os mesmos encarregados de se organizarem para o início da partida. Após formação das equipes, foi distribuído fichas com as regras. Após a leitura, foi disponibilizado um momento para responder possíveis dúvidas quanto às regras do jogo, esse foi um período de interação entre os grupos, onde uns respondiam as dúvidas de outros participantes. O fato de deixar os adolescentes descontraídos, possibilita uma inserção natural na atividade. A importância de iniciar um jogo com um ambiente menos rigoroso e mais tranquilo faz com que a atividade tenha um aspecto prazeroso, isso pode deixar os estudantes mais aptos a desenvolver sua iniciativa e criatividade durante todo o desenvolvimento da atividade (LUCKESI, 2014).

Para dar início à partida, um participante de cada equipe teve que retirar uma carta desafio no monte de cartas, que foi lida em voz alta por um membro da equipe. Após a leitura dessa carta a problematização inicial foi lançada aos adolescentes, que foi reunir cartas formação que possibilitasse a montagem de uma fitofisionomia do bioma Cerrado. A carta desafio funciona como um agente gerador de diversas questões sobre fatores bióticos e abióticos do Cerrado. Essa problematização tem por finalidade permitir que os estudantes percebam a necessidade de adquirir novos conhecimentos para atingir seu objetivo no jogo. Delizoicov e Angotti (1990, p. 29) sugerem que a postura do educador nesse momento deve se voltar mais para "questionar e lançar dúvidas sobre o assunto que para responder e fornecer explicações". Explicam, ainda, que o critério para a escolha das questões é o seu vínculo com o conteúdo a ser desenvolvido, ou seja, as questões devem estar necessariamente relacionadas com o conteúdo do bioma Cerrado.

No segundo momento pedagógico, identificado como "Organização do Conhecimento", o objetivo da equipe foi selecionar uma sequência de cartas que fossem correspondentes a uma fitofisionomia do Cerrado sorteada antes de iniciar a partida. Essas cartas denominadas de carta formação possuem informações do Cerrado, tais como: tipo de solo; estrato vegetal; espécies animais; espécies vegetais; características gerais e identificação da fitofisionomia. Para ter acesso às cartas formação, os participantes tiveram acesso a carta pergunta, que ao serem respondidas, promovia o conhecimento sobre ecologia e características do Cerrado. Os 
estudantes também tinham acesso a carta biblioteca que servia como fonte de pesquisa, que lhes davam direito a ter acesso a informações importantes que poderiam ajuda-los na escolha da carta formação correta. Delizoicov e Angotti (1990) explicam que, no segundo momento, os conhecimentos necessários para a compreensão do tema e da problematização inicial deverão ser sistematicamente estudados sob orientação do professor.

Ao acertarem as respostas da carta pergunta, as equipes podiam avançar no jogo, independente do lançamento dos dados. Quando uma equipe errava a resposta da pergunta, era motivo para as demais equipes informarem a alternativa correta, esse foi uma ocasião que permitiu aos estudantes uma troca de informações que resultou na correção dos conceitos ecológicos adquiridos durante as aulas de ecologia. Esta dinâmica, como sugerido por Malaquias e Ribeiro (2013) permite aos estudantes uma facilidade em trocar informações, agindo como um elo integrador entre a diversão e o processo de aprendizagem. Como resultado há um bom relacionamento social dentro da sala de aula, podendo ser observado um ambiente de cordialidade e respeito entre os adolescentes.

No terceiro e último momento pedagógico "Aplicação do Conhecimento", as equipes reuniram o máximo de características ambientais para construir a sua fitofisionomia. Para Kishimoto (2017) as atividades lúdicas despertam ações extremamente dinâmicas nos estudantes, isso se dá devido à alta interação que ocorre entre os participantes. Uma atividade lúdica sendo aplicada seguindo os Três Momentos Pedagógicos intensifica e propicia ao estudante ser reconhecido como um personagem central no processo de estruturação do conhecimento, pois a problematização faz com que o adolescente dialogue, discuta e se mobilize para organizar e aplicar o seu conhecimento. Com esse cenário, cabe ao professor, propor ferramentas que conduza o estudante para uma pesquisa efetiva e direcionada sobre um tema estabelecido. Com este cenário, pretendeu-se que o estudante, de forma "dinâmica e evolutivamente" fosse capaz de perceber que o conhecimento além de ser uma construção historicamente determinada, está acessível para qualquer cidadão e, por isso, deve ser apreendido, para que possa fazer uso dele. Assim, "pode-se evitar a excessiva dicotomização entre processo e produto, física de 'quadro-negro' e física da 'vida'" (DELIZOICOV; ANGOTTI, 1990, p. 31).

Ao final da partida, cada equipe apresentou aos demais participantes de forma oral a sua fitofisionomia. A apresentação da fitofisionomia possibilitou a verificação de erros e acertos durante a aplicação da atividade, bem como, compreender as semelhanças e diferenças das fitofisionomias que formam o bioma Cerrado. Durante a apresentação das fitofisionomias de 
cada equipe, foi avaliado o desenvolvimento cognitivo dos estudantes, com base na Taxonomia de Bloom.

A primeira categoria proposta pela Taxonomia de Bloom do Domínio Cognitivo é a categoria "Lembrar". Antes do início da partida, foram sorteadas as cartas desafio para cada equipe. Foi um momento em que a equipe se reuniu para levantar as primeiras características referentes à sua fitofisionomia. Ao receberem as cartas, foram registrados os seguintes comentários de uma equipe:

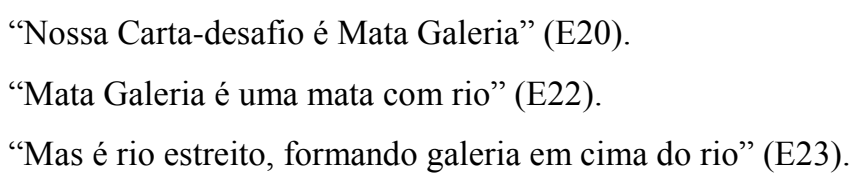

A fala dos estudantes evidencia que foram recordados conceitos já estudados sobre o bioma, como as características das matas de galerias. Desta forma, observa-se que os estudantes foram capazes de recordar informações, quanto às características do bioma, além de outros conceitos ecológicos necessários para dar continuidade ao jogo. Lembrar conceitos e fatos é requerido como um conhecimento prévio, importante para que um indivíduo possa organizar o seu conhecimento.

Na aplicação do jogo, a categoria "Lembrar" serviu para que os estudantes pudessem definir as características mais marcantes da fitofisionomia. No momento que uma informação era anunciada pelo grupo, era possível determinar outras características necessárias criando condições para estabelecer uma relação entre as informações, com isso levando a formação do conhecimento. Esta categoria não significa que o adolescente decorou ou memorizou uma informação, ela possibilita identificar a relevância da informação. É preciso trazer a consciência esse conhecimento dos estudantes, e reuni-los para posteriormente dar significado a esses termos recordados (FERRAZ; BELHOT, 2010).

A segunda categoria proposta pela Taxonomia de Bloom foi "Entender". Os participantes da "Trilha do Cerrado" foram capazes de interpretar a informação recebida. Por exemplo, ao tirar uma carta biblioteca com o tema serapilheira contendo a seguinte informação:

“Camada de material orgânico ou em decomposição presente na superfície do solo de florestas, sendo formada por uma infinidade de materiais como folhas, galhos, flores, frutos, sementes e dejetos de animais." (Carta-biblioteca)

Certamente o estudante já ouviu sobre a necessidade de a planta perder folhas para economia de água, isso é visto no tema Fisiologia Vegetal, no entanto, ao receber essa informação cabe ao participante lembrar-se do processo e entender a sua utilidade junto às árvores do Cerrado. No decorrer do jogo ao pegar uma carta pergunta que questionava em qual 
tipo de formação vegetal possuía maior quantidade de serapilheira, coube ao estudante interpretar a informação que recebeu e colocar em prática. Ao ser questionado qual fitofisionomia do bioma possuía maior quantidade de serapilheira, um estudante disse:

"Serapilheira são folhas no chão, então na mata possui quantidade média de serapilheira" (E5).

Durante a aplicação do jogo, ao responderem as perguntas, lembraram-se de conceitos sobre ecologia do Cerrado, como também relacionaram o conceito adquirido com o ecossistema em estudo. Com base na Taxonomia de Bloom, os estudantes recordaram conceitos e posteriormente foram capazes de compreender. A categoria "Entender" caracteriza-se como sendo o nível para construção de significados por meio da interpretação obtida por intermédio da linguagem oral, escrita ou gráfica. É nesse momento que a informação é compreendida pelos participantes do jogo. Os adolescentes deduziram um contexto diferente do que usam em sala de aula.

A terceira e última categoria analisada nesse experimento foi a categoria "Aplicar". Os conhecimentos dos estudantes foram utilizados para resolver um problema, a construção de uma fitofisionomia do Cerrado a partir das cartas com todas as características possíveis. Durante a categoria "Aplicar", os participantes identificaram erros que ocorreram durante a fase de "Organização do Conhecimento", nos Três Modelos Pedagógicos.

$\mathrm{Na}$ apresentação da carta formação para a fitofisionomia mata seca, a equipe apresentou o seguinte comentário:

"Na Mata Seca, as árvores são perenifolias... Mas espera, está errado, as folhas das árvores caem na época seca, elas são caducifolias. Pegamos a carta errada" (E18).

No momento da apresentação, os estudantes tinham em posse as duas cartas biblioteca com os temas: Perenifolias e Caducifolias. Essas cartas apresentavam o conceito de Fisiologia Vegetal aplicado a Ecologia do Cerrado. Infelizmente, nos livros didáticos não há uma integração de conteúdos, perenifolia e caducifolia abordados na $2^{\mathrm{a}}$ série do ensino médio na unidade de Fisiologia Vegetal. Assim, caberia à unidade Ecologia ( $3^{\mathrm{a}}$ série do ensino médio), retomar esse conceito para abordar a fisiologia das plantas do Cerrado. No entanto, as características fisiológicas das plantas não são mencionadas nos livros didáticos (BEZERRA; SUESS, 2013). Os participantes tiveram que aplicar um conhecimento numa situação nova, explicando um processo.

Os participantes aplicaram de forma correta o conhecimento que entenderam e que conseguiram recordar durante a apresentação da sua fitofisionomia. Outro exemplo foi à equipe 
que apresentou a fitofisionomia campo sujo. Após explicar corretamente as características gerais dessa fitofisionomia, assim como o estrato vegetal, era o momento de apresentar o tipo de solo encontrando no campo sujo:

"No campo sujo, o solo tem muita matéria orgânica, possui cor escura" (E23)

"Tá errado" (E28).

Neste momento, o professor interviu no debate:

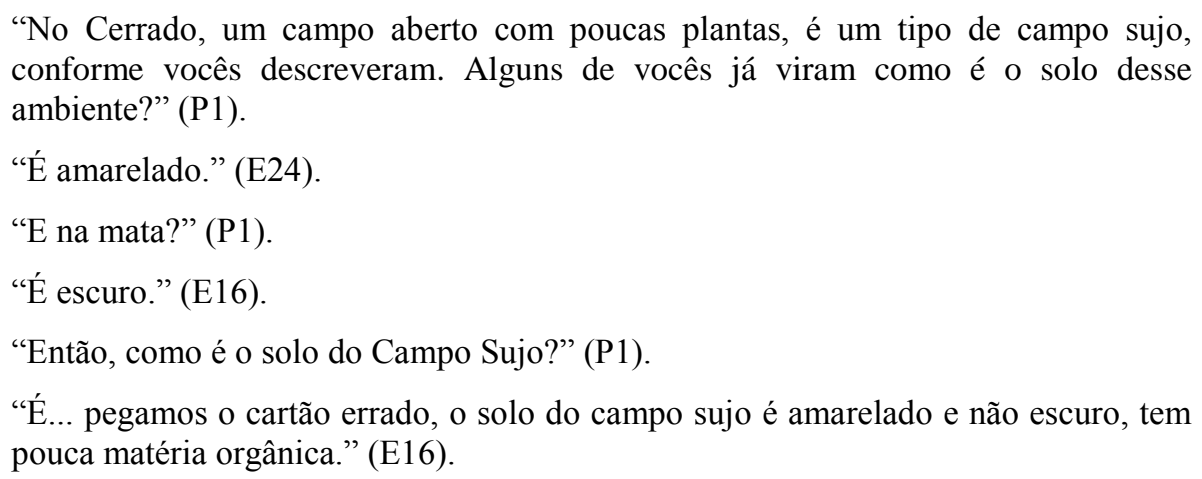

Nessa categoria os estudantes aplicaram um conhecimento compreendido, o tipo de solo da fitofisionomia. No momento da apresentação da fitofisionomia um participante complementou que "possui cor escura", imediatamente, outro adolescente disse que não estava correto essa informação, e assim iniciou-se um debate dentro da equipe. Por fim, o próprio grupo identificou o erro e apontou a informação correta. Mesmo pegando uma carta formação errada, ao aplicar de forma correta o conhecimento compreendido, foi detectado que o fluxo de conhecimento cognitivo foi alcançado, obedecendo ao que é definido pela Taxonomia de Bloom.

As equipes chegaram a selecionar algumas cartas que não tinham relação com a sua fitofisionomia desafio, mas identificaram onde estava o erro e no momento da apresentação, identificaram a falha e utilizaram para implementar na sua fitofisionomia a informação correta. É compreensível a escolha de carta formação errada para fatores distintos de cada fitofisionomia pois, este tema é pouco explorado nos livros didáticos e consequentemente, pouco abordados nas aulas de Biologia no ensino médio (BEZERRA; SUESS, 2013).

Após a aplicação do jogo, os participantes foram questionados sobre a importância do da atividade na aplicação do conteúdo. Todos estudantes responderam que o jogo "Trilha do Cerrado" foi importante na aplicação do conteúdo sobre o bioma Cerrado. Mascarenhas (2010) ressalta que as informações sobre o Cerrado estão restritas a livros didáticos, e a falta de bibliografias que complementam o estudo desse bioma faz com que atividades como jogos sejam tão valorizados. Fazer com que os adolescentes conheçam as características de um 
determinado ecossistema e dessa forma possuir instrumentos para uma conscientização ambiental é primordial para a formação de cidadãos críticos (SCHALL, 1994).

Os participantes enfatizaram que o jogo minimizou momentos de distração que geralmente ocorrem durante aulas expositivas, conforme pode ser observado nos seguintes relatos.

"Porque através desse jogo a gente pode aprender coisas que talvez ouvimos mas nem tudo sabemos" (E2)

"Na aula há momentos em que não prestamos atenção e não aprendemos certas coisas, com o jogo aprendemos diversas coisas além de relembrá-las" (E5).

O jogo desenvolveu a atenção, deixando os estudantes mais interessados na aula. Durante a partida foi preciso se concentrar para a realização das jogadas, e dedicar atenção para ouvir outros membros da própria equipe, ou da equipe oponente, podendo intervir nas respostas. Esta dinâmica difere das aulas expositivas, no qual o estudante apenas assiste uma explanação, podendo interromper o professor para realizar perguntas. Miranda, Gonzaga e Costa (2016), informam que aulas nos moldes tradicionais de transmissão de conhecimento não conseguem levar os estudantes a desenvolverem um pensamento crítico que os levem a uma conscientização para resolução de problemas. Desta forma, os professores devem buscar estratégias de ensino-aprendizagem que possa envolver e motivar os discentes, evitando colocar os adolescentes como meros ouvintes. A passividade dos estudantes pode resultar em momentos de distração e com isso, perder a sequência do tema estudado (RAHAL, 2009).

Usando um jogo de tabuleiro como linguagem comum, o conhecimento pode ser integrado e diferentes visões podem ser discutidas. Assim, pode-se sugerir que os jogos podem ter uma finalidade semelhante à modelagem formal; embora os modelos permitam representações muito mais complicadas. Ao falar sobre um jogo, os estudantes e professores podem obter feedback sem o risco de se perder em questões técnicas.

Questionados sobre a abordagem no jogo "Trilha do Cerrado" com relação aos conteúdos estudados, os estudantes responderam que o tema foi visto em sala de aula, no entanto, com o jogo ficou mais fácil assimilação e compreensão do conteúdo.

\footnotetext{
"Havíamos estudado em sala de aula" (E7).

“Já tinha estudado esse assunto, mas com o jogo ficou mais claro de entender." (E17).

"Porque o jogo ajuda entender melhor o que passou" (E26).
}

Wolski (2013) aponta que atividades lúdicas são instrumentos que funcionam como reforço para conceitos já estudados. Em adição, Campos, Bortoloto e Felício (2003) defendem que o uso de jogos didáticos atua como uma forma de preencher espaços deixados pelo processo 
de transmissão-recepção de conteúdo. Por esse motivo, os estudantes afirmaram que assuntos que já haviam estudados, ficaram mais claros. O jogo sendo utilizado como uma ferramenta lúdica é uma potencial ferramenta para a revisão de conteúdos (BRAGA; MATOS, 2013; PEREIRA; PEREIRA; MAGALHÃES, 2017). Alguns estudantes registraram também que aprenderam conteúdos novos, não visto em sala de aula.

“Trouxe assuntos novos e conhecimentos novos" (E24),

"No jogo foi possível abranger mais conhecimento e assuntos novos. Bastante dinâmico e possível obter muito conhecimento" (A7).

$\mathrm{O}$ fato de desafiar os participantes do jogo em reunir características de uma fitofisionomia do Cerrado possibilitou aos estudantes adquirir conhecimento das características e fisiologia de espécies do Cerrado. Segundo Bizerril (2003), apesar do bioma Cerrado ser tratado no ensino básico, o mesmo é visto de forma superficial não dando o valor necessário para o conhecimento deste ecossistema. O Cerrado brasileiro é abordado nos livros de Biologia para o ensino médio, em capítulos referentes a Biomas e Domínios Fitogeográficos Brasileiros, no entanto, o tema ocupa uma ou duas páginas desses livros (BEZERRA; SUESS, 2013). É evidente o impacto que causa a falta de informações para a temática no ensino médio, pois vários assuntos importantes para compreensão desse ecossistema não são aplicados. Além do mais, os livros didáticos apresentam as características do bioma cerrado de forma uniforme, não valorizando as diferentes fitofisionomias e suas particularidades (BIZERRIL, 2003; EMMEL; ARAÚJO, 2012).

Ainda avaliando a importância do jogo na aplicação do conteúdo, o jogo didático foi classificado pelos estudantes como uma metodologia "fácil", auxiliando no processo de aprendizagem, conforme pode ser observado no seguinte relato: "O jogo auxilia na aprendizagem de uma forma mais fácil” (E9). Ressaltamos que, cada estudante tem uma forma particular de aprender, o que geralmente é ignorado quando se observa a turma de maneira coletiva. É necessário ao professor criar estratégias que identifique e valorize o processo cognitivo de cada indivíduo (GARDNER; CHEN; MORAN, 2009). O professor deve utilizar de vários mecanismos de ensino, procurando uma metodologia que possa atingir um maior número de estudantes, cada qual com a sua particularidade, que anseiam pelo mesmo interesse, em ter uma educação transformadora no seu modo de agir (KRASILCHICK, 2008).

Quanto aos pontos positivos do jogo, os participantes responderam que o uso de cartas contento perguntas, possibilitou melhorar o processo de ensino-aprendizado: 
"Com jogos força nossos pensamentos a ligarem resposta a imagens e melhora o aprendizado" (A18).

"Os alunos se interagem se reúnem para responder questões dicas que servem como resumindo, facilitam à aprendizagem” (A11).

A dinâmica de pergunta seguida de resposta incentivou os grupos de estudantes a trocar informações para escolher a alternativa correta. Isso permitiu que os participantes participassem das ações para a resolução de um problema. A carta contendo pergunta não teve a função de medir o conhecimento ou a memorização, mas sim como um instrumento de formação, pois as perguntas tinham por objetivo despertar nos estudantes os conceitos. Os estudantes viram na aplicação do jogo um modelo alternativo de aula, ou seja, não foi apenas um momento de diversão, houve aprendizado e entretenimento numa só atividade.

“O jogo nos explica a matéria de uma forma diferenciada e dinâmica. Muito importante, traz um novo método de ensino. O jogo nos ensina de uma forma diferente" (A24).

"Muito interessante um jeito divertido de aprendizagem e trabalho em equipe. Eu gostei é um novo jeito de aprendizagem" (E8).

O uso de atividade lúdica permitiu aos estudantes aprender de forma leve e natural, fugindo das tensões e cobranças que pode ocorrer durante uma aula expositiva. Para os participantes, o jogo agiu como uma fonte de aprendizado e não somente como uma avaliação sobre o conteúdo. Quando questionados sobre o relacionamento com os colegas durante a aplicação do jogo, os adolescentes responderam que estudantes que não tinham intimidade em sala de aula, se relacionaram e se conheceram melhor, durante a aplicação.

\footnotetext{
"Movimentação descontraída, houve mais união entre colegas" (E14),

“O jogo é bastante legal porque através dele aprendemos ter união entre os colegas que não falamos muito" (E2),

"Bem estabelecida, pois permite uma maior competitividade e interação entre os alunos. Pois permite maior aprendizagem e interação entre os alunos" (E12).
}

A falta de socialização com pessoas fora do ciclo de amizade pode ocasionar isolamento social. Atividades lúdicas, agem quebrando possíveis barreiras sociais que ocorrem numa sala de aula. Com a aplicação do jogo houve interesse dos adolescentes em trocar experiências e conhecimentos. Segundo Kishimoto (2017), ao jogar, os estudantes se relacionam, tirando dúvidas, trocando experiências e possibilitando um ambiente cordial. Isso contribui para o desenvolvimento pessoal e social do adolescente, facilitando o processo de socialização entre grupos. 


\section{CONSIDERAÇões FINAIS}

O jogo Trilha do Cerrado permitiu aos estudantes a possibilidade de participação em uma atividade lúdica, resultando num momento de descontração e aprendizagem de conceitos sobre o bioma Cerrado. Atividades lúdicas raramente são exploradas no ensino médio, inclusive nas aulas de Biologia, por isso os estudantes demonstraram insegurança em participar da atividade. No entanto, ao final da aplicação do jogo, os participantes mostraram-se entusiasmados e apresentaram ideias para melhorar a sua dinâmica. A realização da atividade contribuiu para relembrar conceitos já estudados sobre o bioma ao relacionar conceitos da Ecologia ou da Fisiologia Vegetal aplicada ao Cerrado. Foi possível observar que os estudantes aprenderam conceitos novos.

O ensino do bioma Cerrado a partir de uma atividade lúdica apresentou-se como uma forma alternativa de estudar este conteúdo, contribuído por meio da dinâmica de perguntas e respostas, debates e escolha de estratégias para avançar no tabuleiro, para cumprir um desafio proposto no início da partida. A aplicação do jogo "Trilha do Cerrado" desenvolveu nos estudantes um perfil de colaboração ao invés de competição, essa característica é fundamental para um jogo pedagógico, permitindo ao adolescente o interesse em jogar outras partidas, pois em nenhum momento o participante é desmotivado.

O uso de um jogo para o trabalhar o ensino do bioma Cerrado, apresentou-se como uma ferramenta de aprendizagem ativa, com implicações positivas no processo de ensino aprendizagem. Jogos com função pedagógica pode ser utilizado não somente para temas ecológicos e sim para todos os demais conteúdos da Biologia.

\section{REFERÊNCIAS}

BARDIN, Laurence. Análise de conteúdo. 3a. Lisboa: Edições, v. 70, p. 223, 2004.

BARROS, Aidil J. da Silveira; LEHFELD, Neide A. de Souza. Fundamentos de metodologia científica: um guia para a iniciação científica. São Paulo: Makron Books, 2000 .

BEZERRA, Rafael Gonçalves; SUESS, Rodrigo Capelle. Abordagem do bioma Cerrado em livros didáticos de Biologia do Ensino Médio. HOLOS, v. 1, p. 233-242, 2013. Disponível em: https://doi.org/10.15628/holos.2013.1289 Acessado em: 25 maio 2020.

BIZERRIL, Marcelo Ximenes Aguiar. O cerrado nos livros didáticos de geografia e ciências. Ciência hoje, v. 32, n. 192, p. 56-60, 2003.

BRAGA, Rodrigo Gomes; MATOS, S. Kronus: Refletindo sobre a construção de um jogo com viés investigativo. Experiências em Ensino de Ciências, v. 8, n. 2, p. 701-719, 2013. 
CAMPOS, Luciana Maria Lunardi et al. A produção de jogos didáticos para o ensino de ciências e biologia: uma proposta para favorecer a aprendizagem. Caderno dos Núcleos de Ensino, v. 47, p. 47-60, 2003.

CARVALHO, Aurilene Maria de Souza; SILVA, Dianne Michelle Alves. Abordagem do Bioma Cerrado nos livros didáticos do Ensino Médio. Experiências em Ensino de Ciências, v. 14, n. 3, 2019. Disponível em:

http://if.ufmt.br/eenci/artigos/Artigo_ID671/v14_n3_a2019.pdf. Acessado em: 23 maio 2020.

CHENG, Meng-Tzu; ANNETTA, Len. Students' learning outcomes and learning experiences through playing a Serious Educational Game. Journal of Biological Education, v. 46, n. 4, p. 203-213, 2012. Disponível em: https://doi.org/10.1080/00219266.2012.688848. Acessado em: 23 maio 2020.

CHENG, Meng-Tzu; ROSENHECK, Louisa; LIN, Chen-Yen; KLOPFER, Eric. Analyzing gameplay data to inform feedback loops in The Radix Endeavor. Computers \& Education, v. 111, p. 60-73, 2017. Disponível em: https://doi.org/10.1016/j.compedu.2017.03.015. Acessado em: 23 maio 2020.

CRISP, Mike. Biome assembly: what we know and what we need to know. Journal of Biogeography, v. 33, n. 8, p. 1332-1333, 2006. Disponível em: https://doi.org/10.1111/j.1365-2699.2006.01551.x. Acessado em: 23 maio 2020.

DE BYL, Penny; BRAND, Jeffrey E. Designing games to motivate student cohorts through targeted game genre selection. In: Handbook of research on improving learning and motivation through educational games: Multidisciplinary approaches. IGI Global, 2011. P. 567-582.

DEDE, Chris. Immersive interfaces for engagement and learning. Science, v. 323, n. 5910, p. 66-69, 2009. Disponível em: https://science.sciencemag.org/content/323/5910/66/tab-pdf. Acessado em: 23 maio 2020.

DELIZOICOV, Demétrio; ANGOTTI, José André. Metodologia do Ensino de Ciências. 1990.

EMMEL, Rubia; ARAÚJO, Maria Cristina Pansera de. A pesquisa sobre o livro didático no Brasil: contexto, caracterização e referenciais de análise no período 1999-2010. ANPED Sul, v. $9,2012$.

FERRAZ, Ana Paula do Carmo Marcheti; BELHOT, Renato Vairo. Taxonomia de Bloom: revisão teórica e apresentação das adequações do instrumento para definição de objetivos instrucionais. Gestão \& Produção, v. 17, n. 2, p. 421-431, 2010. Disponível em: http://dx.doi.org/10.1590/S0104-530X2010000200015 Acessado em: 25 maio 2020.

GARDNER, Howard; CHEN, Jie-Qi; MORAN, Seana. Inteligências Múltiplas. Penso Editora, 2009.

GARRIS, Rosemary; AHLERS, Robert; DRISKELL, James E. Games, motivation, and learning: A research and practice model. Simulation \& Gaming, v. 33, n. 4, p. 441-467, 
2002. Disponível em: https://doi.org/10.1177/1046878102238607. Acessado em: 23 maio 2020 .

JEAN JUSTICE, Lenora; RITZHAUPT, Albert D. Identifying the Barriers to Games and Simulations in Education: Creating a Valid and Reliable Survey. Journal of Educational Technology Systems, v. 44, n. 1, p. 86-125, 2015. Disponível em: https://doi.org/10.1177/0047239515588161. Acessado em: 23 maio 2020.

KISHIMOTO, Tizuko M. Jogo, brinquedo, brincadeira e a educação. Cortez editora, 2017.

KOLB, David A. Experiential learning: Experience as the source of learning and development. FT press, 2014.

KRASILCHIK, Myriam. Prática de ensino de Biologia - $4^{\circ}$ ed. rev. e ampl.. $2^{\circ}$ Reimpr.-São Paulo: Editora da Universidade de São Paulo, 2008.

LUCKESI, Cipriano Carlos. Avaliação da aprendizagem escolar: estudos e proposições. Cortez editora, 2014.

MASCARENHAS, Luciane Martins de Araújo. A tutela legal do bioma cerrado. Revista UFG, v. 12, n. 9, 2010. Disponível em:

https://files.cercomp.ufg.br/weby/up/694/o/09_Atuteladobiomacerrado.pdf Acessado em: 25 maio 2020.

MIRANDA, Jean Carlos; GONZAGA, Glaucia Ribeiro; COSTA, Rosa Cristina. Produção e avaliação do jogo didático "Tapa Zoo" como ferramenta para o estudo de zoologia por alunos do ensino fundamental regular. Holos, v. 4, p. 383-400, 2016. Disponível em:

https://www.redalyc.org/pdf/4815/481554867033.pdf Acessado em: 25 maio 2020.

NUNES, Alexandre Ferreira. Jogo didático para ensino do bioma cerrado. 2020. $103 \mathrm{f}$. Brasília: Dissertação (Mestrado Profissional no Ensino de Biologia) - Universidade de Brasília, Brasília, 2020.

PAPASTERGIOU, Marina. Digital game-based learning in high school computer science education: Impact on educational effectiveness and student motivation. Computers \& Education, v. 52, n. 1, p. 1-12, 2009. Disponível em: https://doi.org/10.1016/j.compedu.2008.06.004. Acessado em: 23 maio 2020.

PEREIRA, Heloisa Silva Aparecida Barbosa; PEREIRA, Thalita Mendes; MAGALHÃES, Ana Carolina. Síntese Proteica" O Jogo". Revista de Ensino de Bioquímica, v. 15, p. 41-48, 2017.

RAHAL, Fábio Adhemar da Silva. Jogos didáticos no ensino de Física: um exemplo na Termodinâmica. Anais do VIII SNEF, 2009.

RECKIEN, Diana; EISENACK, Klaus. Urban sprawl: Using a game to sensitize stakeholders to the interdependencies among actors' preferences. Simulation \& Gaming, v. 41, n. 2, p. 260-277, 2010. Disponível em https://doi.org/10.1177/1046878108321871. Acesso em 24 maio 2020. 
RIBEIRO, Maiane Santos Malaquias e Suely de Souza. A Importância do Lúdico no Processo de Ensino-Aprendizagem no Desenvolvimento da Infância. Psicologado, [S.1.]. (2013). Disponível em https://psicologado.com.br/atuacao/psicologia-escolar/a-importancia-doludico-no-processo-de-ensino-aprendizagem-no-desenvolvimento-da-infancia. Acesso em 24 maio 2020.

RICHARDSON, Matthew L. Using an Exploratory Internet Activity \& Trivia Game to Teach Students about Biomes. Science Activities, v. 46, n. 2, p. 19-24, 2009. Disponível em: https://doi.org/10.3200/SATS.46.2.19-24. Acessado em: 23 maio 2020.

SCARFE, Neville Vincent. Play is education. Childhood Education, v. 39, n. 3, p. 117-121, 1962. Disponível em: https://doi.org/10.1080/00094056.1962.10726996. Acessado em: 23 maio 2020.

SCHALL, Virginia T. Environmental and health education for school-age children: a transdisciplinary approach. Cadernos de Saúde Pública, v. 10, p. 259-263, 1994. Disponível em:https://www.scielosp.org/article/csp/1994.v10n2/259-263/ Acessado em: 25 maio 2020.

SHABANEH, Yasmin; FARRAH, Mohammed. The effect of games on vocabulary retention. Indonesian Journal of Learning and Instruction, v. 2, n. 01, 2019. Disponível em: https://doi.org/10.25134/ijli.v2i01.1687. Acessado em: 23 maio 2020.

SILVA, Ana Paula Miranda; SILVA, Maria Francilene Souza; ROCHA, Francinalda Maria Rodrigues; ANDRADE, Ivanilza Moreira. Aulas práticas como estratégia para o conhecimento em botânica no ensino fundamental. Holos. Rio de Janeiro, v.8, 2015. Disponível em: https://doi.org/10.15628/holos.2015.2347. Acessado em: 23 maio 2020.

SKILBECK, Adrian. Dewey on Seriousness, Playfulness and the Role of the Teacher. Education Sciences, v. 7, n. 1, p. 16, 2017. Disponível em: https://doi.org/10.3390/educsci7010016. Acessado em: 23 maio 2020.

VALENČIČ ZULJAN, Milena; VOGRINC, Janez. Facilitating effective student learning through teacher research and innovation. 2010. $322 \mathrm{f}$. Tese de Doutorado. Univerza v Ljubljani, Pedagoška fakulteta, 2010. Disponível em https://repozitorij.unilj.si/IzpisGradiva.php?id=69328. Acessado em: 23 maio 2020.

WOLSKI, Zilma do Belém. Atividades lúdicas de aprender e brincar com as células. Os desafios da escola pública paranaense na perspectiva do professor PDE - Produto didático pedagógico. Secretaria da Educação. Estado do Paraná. Palmital, v.2, 2013.

Recebido em: 28 de maio de 2020. Aprovado em: 23 de agosto de 2020. 